\title{
Population dynamics of an island population of water voles Arvicola amphibius (Linnaeus, 1758) with one major predator, the eagle owl Bubo bubo (Linnaeus, 1758), in northern Norway
}

\author{
Karl Frafjord' ${ }^{1}$ (1)
}

Received: 18 February 2021 / Revised: 27 October 2021 / Accepted: 28 October 2021 / Published online: 9 November 2021

(c) The Author(s) 2021

\begin{abstract}
Predator-prey relationships are of great significance to ecosystems, and their effects on the population dynamics of voles and lemmings (Microtinae) in Boreal and Arctic environments have long been of particular interest. A simple ecosystem with one major prey and one major predator could be an ideal setting for a study of their interactions. This is the situation on several small islands on the coast of northern Norway just below the Arctic Circle, with populations of water voles Arvicola amphibius preyed upon by the eagle owl Bubo bubo. The population dynamics of the water vole was studied by trapping and tagging in 2003-2018, eagle owl pellets were collected for analyses, eagle owl breeding attempts were recorded, and some weather variables collected from official recordings. After having been introduced well into the study period, the number of sheep Ovis aries was also recorded. Water voles were the main prey of the eagle owl, with $89 \%$ occurrence in pellets, with an overrepresentation of adults and males. Both predation, sheep grazing and extreme weather events influenced the vole population. Predator exclusion, as happened in three summers due to an intensive radio tracking study, especially increased the number of surviving young (in particular from the early cohorts) and the mass of adults. Extreme weather events, such as flooding in summer and deeply frozen ground in winter, most significantly reduced vole populations. Sheep grazing may exacerbate the effects of predation. A similar multitude of factors may affect populations of other rodent species as well.
\end{abstract}

Keywords Predator-prey relationship $\cdot$ Population dynamics $\cdot$ Predation $\cdot$ Sheep grazing $\cdot$ Weather extremes

\section{Introduction}

Population fluctuations in voles and lemmings (Cricetidae) have attracted a lot of scientific attention for more than 100 years (reviewed by Hanski and Henttonen 2002; Krebs 2013; Boonstra et al. 2016; Oli 2019). The objectives have been both to explain such fluctuations in small rodents and to generate hypotheses about population regulation in general. Voles and lemmings are important parts of many food chains and ecosystems, and some voles may damage agricultural crops in so-called outbreak years. Cycles are particularly prominent at northern latitudes, both boreal and Arctic (Henttonen 1977; Hansen et al. 1999; Boonstra and Krebs 2012; Krebs 2013). Among mammals, voles, and lemmings

Karl Frafjord

karl.frafjord@uit.no

1 Troms $\emptyset$ University Museum, UiT The Arctic University of Norway, P.O. Box 6050 Langnes, 9037 Troms $\varnothing$, Norway are re-selected with a tremendous potential for a high reproductive output and peak years are often characterized by a 10- to 100-fold increase in density (Henttonen 1977; Hörnfeldt 2004). When population growth is the nature of most vole species, why are outbreaks the exception rather than the rule? Exploding population growth rates are rarely seen in nature, a fact that introduces regulatory forces such as predators, weather, diseases and parasites, food quantity and quality and intrinsic social factors (Erlinge et al. 1983; Hanski et al. 1991; Korpimäki and Norrdahl 1991; Hansen et al. 1999; Krebs 2013; Oli 2019). Predation may have a large impact on a small population and may potentially halt a population increase, but becomes insignificant in a large population due to predator satiation. Predators respond slowly and are often territorial, thus limiting their density and impact on the vole population (Krebs 2013).

The water vole Arvicola amphibius (Linnaeus, 1758) is a large member of the group "small rodents", with an adult body mass around $200 \mathrm{~g}$. It is not as well studied as some other voles, despite having dramatic population fluctuations 
and being regarded as a pest in many agricultural regions (Saucy 1994; Cerqueira et al. 2006). Because animals with larger body size in general tend to have slower individual and population growth rates, size may at least potentially affect the length of the population cycle (Krebs 2013). In captivity, female and male water voles had a mean lifespan of 368 and 393 days, with maximum 1100-1200 days (Nazarova 2013). Litter size at birth was around 4.3 and females had around four litters in their lifespan. Young born in spring could reproduce in the summer, but not those born later (Nazarova 2013). Food availability may influence water vole growth rates and mass at sexual maturity, and increased density may reduce maturation rates (Moorhouse et al. 2008).

Over a 16-year period, I studied water voles living on small islands on the coast of northern Norway where there was only one major predator, the eagle owl Bubo bubo (Linnaeus, 1758). This predator-prey system was very simple, consisting basically of one prey and one predator, and could theoretically throw light on the mechanisms driving population changes and contribute to unraveling the prey-predator relationship (sensu Melis et al. 2011). The sedentary eagle owl is a formidable and efficient predator of water voles (Frafjord 2014).

The main aim of the study was thus to study the effects of predation on the population of water voles. Because eagle owls do not breed every year, this could also work as a natural experiment: assuming that breeding would lead to increased predation of water voles relative to nonbreeding. I predicted that the eagle owl would significantly and negatively affect both the survival of water voles and consequently, the production of young (sensu Hanski and Henttonen 2002; Norrdahl et al. 2004; Getz et al. 2006). Predation, or increased predation, could have a stabilizing effect on the water vole population, in particular by reducing numbers in peak years with both a numerical (in terms of owlet survival) and functional response (Erlinge et al. 1983). In return, by killing voles of the future breeding segment before they were able to breed, the eagle owl could reduce the amount of food available to itself at later stages and hence, its own breeding success. Locally, the eagle owl is a sedentary specialist predator on water voles (sensu Hanski et al. 1991; Korpimäki and Norrdahl 1991, 1998). During the study, domestic sheep Ovis aries were unfortunately introduced into the study area. Sheep may have a profound effect on the population of water voles similar to predation, both through food competition and by reducing the vegetation cover that protects voles against predation (Frafjord 2014).

I studied the effects of several factors on both the number of voles and their mass (sensu Carlsen et al. 2000), by comparing between years and generally predicting that bad weather, increased predation, and increased grazing of sheep would affect the water vole negatively. I predicted that the owl's most significant impact would be on the number of voles surviving the winter, hence, the number of potential breeders in the following spring. I also predicted that the owl would reduce the number of early cohorts of voles more than later cohorts. I predicted that the effects of predation would differ slightly to that of grazing by sheep, especially regarding the survival of the first cohorts. Lastly, I predicted that the water vole may adapt its daily activity somewhat to avoid eagle owl predation.

\section{Materials and methods}

\section{Study area}

The Solvær archipelago is situated on the coast of Helgeland, North Norway, just below the Arctic Circle $\left(66^{\circ} 21^{\prime} \mathrm{N}\right.$, $12^{\circ} 36^{\prime} \mathrm{E}$, Fig. 1). This archipelago consists of numerous small and large islands. Old, cultivated fields still remain on several islands and are of particular interest for this study because these grassy fields were preferred by the water vole and housed most of the islands' populations. The natural vegetation of heather and marshy areas appeared to be marginal for water voles, with only small numbers inhabiting them. The water vole was the only mammal living on these islands, except the occasional otter Lutra lutra.

When I started trapping water voles in 2003 , some exploratory work was done to locate a suitable study area, test trap efficiency, and find the optimal trapping periods. The initial trappings were done on Lille Buøya, Sør-Solvær, NordSolvær, and Storrossøya (Fig. 1). Because all these populations crashed, none of these islands were found suitable for this study. In the following years the sites on Lille Buøya and Storrossøya were, however, surveyed for signs of water voles (sensu Frafjord 2014) every year. Traps were used on a fifth island, Gammholmen, in 2006 and this site was also surveyed every summer thereafter (Fig. 1). In 2014, a survey of a large number of islands was made to study the effects of sheep grazing (Frafjord 2014).

In 2005, the island Trolløya was selected as the study site (Fig. 1). Domestic sheep had been grazing on this island until a couple of years before 2005, but they were absent when I started the study. The total study area across all years was estimated to be $14372 \mathrm{~m}^{2}$ by the minimum convex polygon (MCP, 100\%) method for trap sites. The trapped area in any particular year was smaller than this, but of similar size in most years except 2007 when it was notably smaller. Adjacent to the study area, there was excellent vole habitat covering an additional $17600 \mathrm{~m}^{2}$ (measured by the area tool in www.norgeskart.no). The rest of the island was much less suited for water voles with only a very low density. Most of the study area was bordered by sea (closed), and only about $25 \%(90 \mathrm{~m})$ of its circumference $(361 \pm 19 \mathrm{~m})$ was open to 


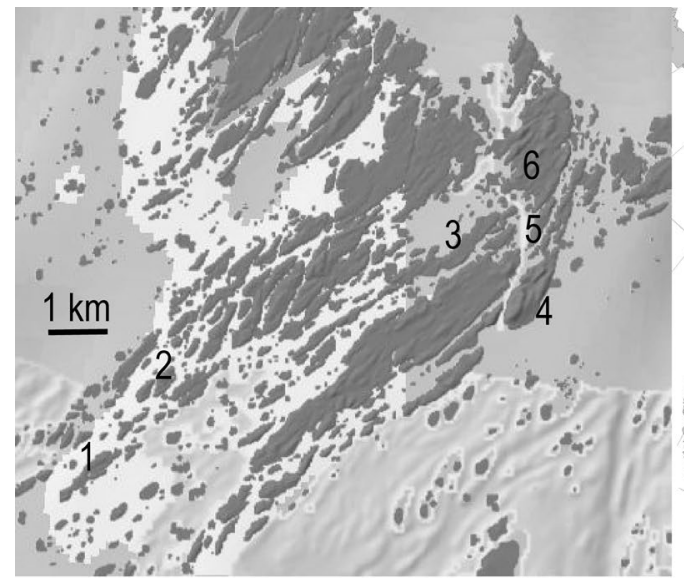

Fig. 1 Map showing the Arctic region (right), the square marks the position of the Solvær archipelago. The enlarged map (left) covers a large part of the Solvær archipelago and islands where water voles were trapped are marked with numbers: 1 Trolløya, 2 Gammholmen,

adjacent suitable vole habitat. An adult male home range could stretch across most of the width of the study area or even beyond, a female home range would occupy around half the width of the study area, and a large-sized juvenile home range around a third (Frafjord 2016).

\section{Trapping}

In the first year, 2003, I experimented with various types of traps, but in 2004 a custom-made trap was selected for this study (Frafjord 2006), with a total of 36 traps. This model was a simple metal funnel box with a hinged wire mesh door, $40 / 30 \times 10 \times 10 \mathrm{~cm}$. I regularly placed the traps at active burrow entrances or in runways and moved the traps successively through the study area over 6-8 days. From 2007, the location of every trapped animal except most recaptures was recorded with a handheld GPS. Because the voles were so easily captured, this study was designed to trap a very large proportion of the population.

In 2005, trapping was only performed in June on Trolløya. During 2006-2008, I used radio transmitters to study water vole home ranges (Frafjord 2016) and spent much time on the site and did more trapping throughout the summer. This study continued in April-May only in 2009. From 2009, I trapped regularly in two periods, first in May and secondly in late July to early August (late August to early September in one year), every year until May 2018 when the study ended.

Captured water voles were aged as juvenile, subadult (overwintered voles that had not reached "breeding size"), or adult. Adults were easily separated from juveniles during most of the season by their size and shaggy coat. For practical reasons, subadults were defined as overwintered voles weighing $<160 \mathrm{~g}$ and adults those $\geq 160 \mathrm{~g}$. Subadults were excluded in some analyses to avoid the effect of differences in the timing of spring growth. Two different samples of juveniles were used, either including or excluding June. This was done to avoid the mostly smaller-sized juveniles in June when needed. Sexing of non-breeders was based on the distance between the anal and urethral openings (Strachan 1998). Trapped voles were weighed in a cotton bag using a Pesola spring scale, 300 or $500 \mathrm{~g}$, with 5 and $10 \mathrm{~g}$ graduation. Voles were marked with a numbered ear tag (National Band and Tag Co., USA, \#1005-1) in one ear and released at the spot of capture. Recaptures were most frequent during the same day or the next few days before the traps were moved further afield. Handling voles took only a few minutes.

To study the voles' daily activity, each capture event was recorded to the nearest hour (including recaptures). Both because the vole may have been trapped during the previous 1-2 $\mathrm{h}$ and to simplify the test, the $24 \mathrm{~h}$ were amended into six 4-h groups. Most trapping was performed during daylight hours, mostly between 0700 and 2300 .

Radio-tracked voles during 2006-2009 (Frafjord 2016) were recorded as being active or passive based on movements or a variable or constant signal strength over a 1-2 min period. Most tracking was done during daytime hours, but all $24 \mathrm{~h}$ was covered at least once per animal, except in April 2009. The total number of fixes was 23,346 (Frafjord 2016).

\section{Predators and competitors}

For some unknown reason, eagle owls did not breed on Trolløya for several years before 2005 (Frode Johansen pers. comm.). One pair started to breed in 2012 and a 
pair attempted to breed in most the following years. Most attempts were, however, unsuccessful with most of the owlets dying early and before becoming fully fledged (at least some in the talons of the white-tailed eagle Heliaeetus albicilla). In most of the years when no breeding occurred, most likely only one adult was present in the summer. Adult eagle owls are resident and very territorial, living in their established territory year-round. One pair's territory was much larger than Trolløya, perhaps ten times larger. When breeding was confirmed, the number of adult owls hunting on Trolløya would be two, with no breeding attempt I assumed only one adult owl hunted there.

In a preliminary study, the eagle owl was shown to prey almost exclusively on water voles (87\% occurrence, Frafjord 2003). The first young water voles appeared above ground in the middle of May, with the majority appearing in June and July. Few voles were born in August or later.

A few other birds of prey likely to hunt water voles were occasionally and very infrequently recorded: the shorteared owl Asio flammeus, kestrel Falco tinnunculus, hobby Falco columbarius, hen harrier Circus cyaneus, and peregrine falcon Falco peregrinus. The mink Neovison vison never reached this archipelago.

Sheep were introduced to Trolløya in spring 2012 and removed in spring 2018. The sheep were of an old, small and semi-wild Norwegian breed, grazing on the island year-round with no supplemental food. The sheep was an unexpected factor and mostly concurred with eagle owl breeding attempts except for one year; in 2017. The results from both factors are presented, but because their effects were nested, no analyses was possible to separate their effects in these years.

The years of study consisted of four categories, as follows:

(1) Three years of intensive radio tracking during the summers of 2006-2008. Human presence may temporarily have reduced hunting by the eagle owl in the study area, and hence reduced predation. The owl is mainly nocturnal, but the bright nights allowed me to work long hours.

(2) Six (for adult voles) and five (for juvenile voles) years with eagle owl (mostly unsuccessful) breeding attempts, 2012-2016, and spring 2018. During these years, sheep were also grazing on the island.

(3) Seven years with sheep grazing on the island 20122018, with the numbers increasing slowly.

(4) Three years with none of the above factors operating, 2009-2011. The first year 2005, could partly be included, but trapping was incomplete as it was only carried out in June.
At least one eagle owl was present every summer, except a large part of the time for those under 1. I compared years that included the factors (1-3) with all other years.

\section{Owl pellet analysis}

Pellets from eagle owls were collected in all years, mostly being found in May. In 2013, the pellets at the nest were collected by other scientists and unavailable to me. It is unknown if this also happened in other years. Before dissection, pellets were soaked and softened in water overnight, and all vole mandibles and fragments of mandibles were collected and counted. In most cases, the number of lower mandibles divided by two was higher than the number of upper mandibles (the cranial part). The highest number of voles for each sample was used.

Other prey items in pellets were mainly birds (see Frafjord 2003). A pellet containing bird remains was considered to contain one bird only, hence, the proportion of birds will be a little underestimated compared to voles. The frequency of occurrence (\%) was based on the minimum number of water vole mandibles and the minimum number of birds. Because the majority of the pellets were found in May (the first few young were trapped in the middle of this month), they mostly represented vole mortality from August to spring, i.e., of the previous year's cohort. I also examined each pellet for water vole ear tags. In the first couple of years this was done by feeling and eye only, then by using an ordinary magnet and later (from 2011) I used a super-magnet onto which the ear tags readily attached.

The mass of voles whose ear tags were found in pellets and recorded on capture, termed the pellet sample, were compared to a selection of the total trapped sample, termed the selection sample. These two samples had the exact same number of voles. The total sample is the total number of voles captured. For the pellet sample, the voles' last recorded masses were used. A selection sample was used for comparison rather than the total sample to avoid a huge difference in sample sizes. For the selection sample, voles from the same cohort (i.e., mass class and age) nearest in trapping schedule to the voles from the pellet sample were selected. Hence, voles eaten by eagle owls were compared to their nearest and most similar fellow in the total sample, although the exact date for the kill was unknown.

\section{Weather variables}

Weather statistics were collected from the site www.eklima.no (downloaded in December 2018 and March 2019). I first collected data from a weather station in Solvær, but this operated only from November 2007 and recorded only temperature. To remedy this shortcoming, I also collected data from a weather station on the island Myken, some $44 \mathrm{~km}$ northwest of Solvær. 
Both temperature, wind, and precipitation were available from this station and downloaded as monthly means. Monthly mean temperatures at the two stations, Solvær and Myken, were highly correlated (Pearson correlation, $r=0.995, p<0.001$, $n=126$ ), hence I used the data from Myken in most tests.

\section{Data analysis}

I compared vole data grouped in different ways. Despite the overall large number of years in this study, grouping years for testing resulted in relatively few in each group, with greater risk of Type II error. From 2007, the position of trapped voles was used to estimate the size of the trapped area (100\% minimum convex polygons, software Biotas 2.0 Alpha). In 2005 and 2006, the sizes of the trapped areas were estimated (the exact trap positions were not noted). Juvenile density was estimated from the number of voles divided by the MCP area and defined as numbers per hectare (ha). Apart from the year 2007, the effective study area was almost identical from year to year, and the length of the open part of the border was estimated to vary with maximum $11 \mathrm{~m}$. This small variation should have little or no consequences for the numbers trapped, allowing for comparisons between years. Some of the voles trapped along the open edge did live both inside and outside the study area, but their proportion should likewise not vary much between years and the purpose was to compare years. Note that the effective study area varied less and was a little larger than the MCP based on precise trap positions, but the last measure also encompass the year 2007.

The actual number of voles trapped was used rather than the more commonly used numbers/100 trap days, because this seemed to be a very good approximation of the population. Because I trapped 10-12 h/day rather than $24 \mathrm{~h}$, moved the traps around, and did not use all traps in every hour of the day, estimating numbers/100 trap days would have required recording the number of traps in use every hour of the day and extrapolating the number of voles caught. Consequently, numbers/100 trap days is much less accurate or even obsolete. This study estimated both the number of adults at the start of or early in the breeding season and the numbers of young and adults late in or at the end of the breeding season. The longterm data from Trolløya was used in all tests. In some tests, data from Storrossøya were included and in a few cases all years and all islands where voles were trapped. Consequently, the sample sizes varied between tests.

\section{Results}

\section{Population dynamics}

A highly significant correlation between the number of firsttime captures and recaptures was found each year (Pearson correlation, $r=0.93, p<0.001, n=19$, Fig. 2), with no particular outliers. This suggests that the trapping effort did not vary between years or with the number of voles in the population, because the relative proportion of recaptures would increase with trapping effort.

The number of young trapped on Trolløya varied fourfold between years, with irregular ups and downs (Table 1; Fig. 2). This variation in numbers did not show the characteristics of a regular cycle, i.e., there was no regular interval between peaks or between crash years and no particular years of increase or decrease leading to these. A good example was the rapid increase from 2010 to 2011 (Table 1; Fig. 2). The number of juveniles was significantly correlated with the number of adults for all islands (Pearson correlation, $r=0.56, p<0.05, n=17$ ), but not for Trolløya alone $(r=0.23, p>0.05, n=13)$. Other islands showed both similar and more dramatic patterns in numbers (Table 2).

Most adults were caught early in the season, with highest numbers in May $(n=409)$ and June $(n=133$, note less trapping in June). From July to early September, 143 adults were caught. The proportion of males caught also declined during the season; 68\% in April (small sample size), $36 \%$ in May to June, and 26\% from July to September (total $n=710$ ).

Adult males during May to September weighed on average $183.6 \pm 30.2 \mathrm{~g}(n=218)$ and females $180.6 \pm 35.4 \mathrm{~g}$ $(n=385)$. The difference of $3 \mathrm{~g}$ was not statistically significant (Paired t test, $t=1.05_{601}, p>0.05$ ). However, males were heavier than females in April and May, whereas females were heavier than males in June and July. In August, they were of equal mass. These differences were tested statistically for the two months with the largest sample sizes and

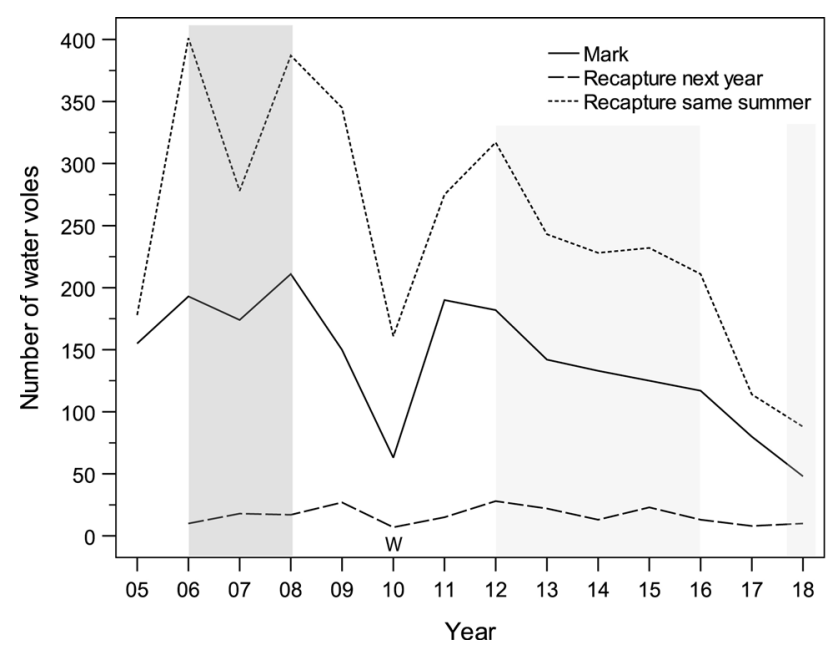

Fig. 2 The number of water voles trapped on Trolløya in 2005-2018. Lines represent three measures; the number of voles marked, the number of recaptured voles marked in the previous year, and the number of recaptured voles marked in the same summer. Dark shading =years of radio tracking, pale shading $=$ years with eagle owl breeding attempts, $\mathrm{W}=$ a particularly cold winter 
Table 1 Mean mass in $\mathrm{g}, 1$ standard deviation (SD) and numbers $(n)$ of adult and juvenile water voles caught on Trolløya in 2005-2018

\begin{tabular}{|c|c|c|c|c|c|c|c|c|c|}
\hline \multirow[t]{2}{*}{ Year } & \multirow[t]{2}{*}{ Factors } & \multicolumn{3}{|l|}{ Adults } & \multicolumn{4}{|c|}{ Juveniles } & \multirow[t]{2}{*}{ Area } \\
\hline & & Mean & SD & $n$ & Mean & SD & $n$ & Density & \\
\hline 2005 & & 199.6 & 22.1 & 52 & (77.5) & (25.9) & (103) & 98.1 & 10,500 \\
\hline 2006 & RT & 208.6 & 21.4 & 32 & 128.9 & 26.9 & $86(171)$ & 162.9 & 10,500 \\
\hline 2007 & $\mathrm{RT}$ & 212.8 & 26.1 & 26 & 110.2 & 31.5 & 147 (166) & 215.6 & 7701 \\
\hline 2008 & RT & 210.3 & 28.5 & 39 & 118.6 & 29.9 & 145 (189) & 153.7 & 12,298 \\
\hline 2009 & & 196.9 & 24.0 & $29(54)$ & 118.5 & 22.8 & 123 & 123.8 & 9938 \\
\hline 2010 & $\mathrm{CW}$ & 172.7 & 26.6 & 18 & 103.8 & 31.7 & 52 & 54.5 & 9535 \\
\hline 2011 & & 187.5 & 24.0 & 41 & 124.9 & 22.7 & 163 (164) & 155.5 & 10,545 \\
\hline 2012 & $\mathrm{~S}+\mathrm{EO}$ & 165.0 & 31.1 & 74 & 93.4 & 20.0 & 136 & 122.6 & 11,088 \\
\hline 2013 & $\mathrm{~S}+\mathrm{EO}$ & 162.1 & 28.6 & 49 & 100.1 & 31.4 & 116 & 111.8 & 10,380 \\
\hline 2014 & $\mathrm{~S}+\mathrm{EO}$ & 150.2 & 29.5 & 35 & 104.1 & 26.8 & 111 & 99.4 & 11,165 \\
\hline 2015 & $\mathrm{~S}+\mathrm{EO}$ & 158.5 & 27.3 & 37 & 89.4 & 37.4 & 111 & 96.5 & 11,499 \\
\hline 2016 & $\mathrm{~S}+\mathrm{EO}$ & 159.5 & 22.3 & 26 & 110.9 & 25.8 & 104 & 108.6 & 9575 \\
\hline 2017 & S & 183.4 & 29.1 & 23 & 105.8 & 36.4 & 65 & 60.1 & 10,810 \\
\hline 2018 & $\mathrm{~S}+\mathrm{EO}$ & 201.9 & 24.6 & 58 & - & & & & 9827 \\
\hline Overall & & 181.4 & 34.7 & 564 & 109.7 & 30.7 & 1359 & 120.2 & 10,383 \\
\hline
\end{tabular}

The density of juveniles (ind. $\mathrm{ha}^{-1}$ ) is also shown. Numbers in brackets for juveniles includes May and June (giving a total $n=1611$ ), the masses of which were not included in statistical tests. In 2005, traps were set in June only. The numbers in bracket for adults include April (not included in mass)

Factors: $R T$ radio tracking, $C W$ cold winter, $S$ sheep present, $E O$ eagle owl breeding attempt. Size of area trapped in $\mathrm{m}^{2}(100 \% \mathrm{MCP})$

\begin{tabular}{|c|c|c|c|c|c|c|c|c|}
\hline \multirow[t]{2}{*}{ Year } & \multirow[t]{2}{*}{ Island } & \multirow[t]{2}{*}{ Crash } & \multicolumn{3}{|l|}{ Adults } & \multicolumn{3}{|c|}{ Juveniles } \\
\hline & & & Mean & SD & $n$ & Mean & SD & $n$ \\
\hline 2003 & L. Buøya & 2003-04 & 188.3 & 19.9 & 12 & 121.5 & 9.6 & $38(67)$ \\
\hline 2003 & N.-Solvær & 2003 & 200.8 & 20.5 & 8 & (61.6) & (18.9) & (26) \\
\hline 2004 & L. Buøya & & & & 0 & & & 0 \\
\hline 2004 & S.-Solvær & 2003 & & & 0 & & & 0 \\
\hline 2004 & Storrossøya & & 196.1 & 17.7 & 22 & 145.2 & 19.2 & $25(100)$ \\
\hline 2005 & Storrossøya & 2005 & 159.7 & 24.6 & 22 & $(75.5)$ & - & (2) \\
\hline 2006 & Gammholmen & No & 184.4 & 24.2 & 10 & 72.4 & 27.8 & 71 \\
\hline
\end{tabular}

Numbers in brackets for juveniles include May and June, the masses of which were not included in statistical tests. Years of population crashes are indicated, when these populations went all but extinct
Table 2 Mean mass in $\mathrm{g}, 1$ standard deviation (SD) and numbers $(n)$ of adult and juvenile water voles caught on five islands in the Solvær archipelago in 2003-2006
Adult mass varied significantly between years (ANOVA, $\left.\mathrm{F}_{3,517}=23.9, p<0.001\right)$, as did juvenile mass from July onwards (ANOVA, $F_{11,1347}=21.4, p<0.001$ ). The mean masses of adults and juveniles were not correlated with their numbers (adults: Pearson correlation, $r=0.06, p>0.05$, $n=14$ years, juveniles: $r=0.19, p=0.57, n=12$ years). The number of young per adult female was correlated with adult mass (Pearson correlation, $r=0.62, p<0.05, n=12$ ). It was $5.6 \pm 2.1$ for Trolløya ( $n=12$ years) and $6.1 \pm 2.6$ for all islands combined $(n=17)$.

The mean size of the study area (MCP method) was about one hectare (Table 1). The average density of juveniles on Trolløya was $120.2 \pm 43.7$ ind. $\mathrm{ha}^{-1}(n=13$ years $)$ and of adults $38.8 \pm 14.4 \mathrm{ind} . \mathrm{ha}^{-1}(n=14)$. The numbers of 
juveniles and adults were not correlated with the size of the trapping area. The difference in juvenile density between the years with maximum and minimum density was by a factor of 3.96. The largest difference between the density of adults ("spring population") and juveniles ("autumn population") in any year was by a factor of 3.47. Consequently, the maximum population difference between years was about the same as the maximum rate of increase within a year.

\section{Number of voles eaten by owls}

A minimum 2147 individual voles and 247 birds were counted in eagle owl pellets. The mean proportion of pellets containing water voles was $89.1 \pm 5.5 \%$ across 16 years and islands, while that of birds was $10.9 \%$. The proportion of voles varied relatively little between years, from 78.4 to $95.5 \%$. For Trolløya, the proportion was $89-95 \%$ in 11 years and $78-80 \%$ in three years. It was not correlated with the number of young or adults of the previous year (Pearson correlation, $p>0.05$ ). The proportion of birds was particularly high (> 20\%) in 2005, 2014 and 2015.

In 2006-2018, 1754 water voles were recorded in pellets from Trolløya, whereas 1611 juveniles were tagged in 2005-2017. The number disappearing from the study area was 1611 juveniles + ca 500 (of 531) adults $=2111$. Because the island's total area of grassland was a little more than twice the size of the study area, less than a half the number of voles eaten by owls was found in the pellets. Hence, a large number of pellets was not found (as should be expected).

A total of 106 ear tags were found in pellets from Trolløya and only two from other islands, equivalent to $8 \%$ of the total number of voles tagged. Including three ear tags from the remains of predated voles, the overall total was 111 . The pellet samples contained tags from 75 juveniles (age at the time of capture) and 36 adults. The proportion of adults to juveniles was nearly twice as large in the pellet sample as in the total sample ( 0.48 vs. 0.23 ). The ratios of adult males to females were 0.71 and 0.64 for the pellet and the total samples, respectively. There was no difference in body mass of voles from the pellet and the selection samples (Table 3).

Overall, the number of ear tags correlated with the number of voles in the pellet sample (Pearson correlation, $r=0.64, p<0.01, n=17)$. When only Trolløya was included, this correlation was even higher $(r=0.72, p<0.01, n=14)$. The number of ear tags from juveniles correlated with the previous year's number of juveniles caught $(r=0.64$, $p=0.02, n=13)$. The number of tags from adults did not correlate with the previous year's number of adults.

\section{Influence of eagle owl and sheep}

Sheep grazed on Trolløya in 2012-2018, when numbers increased from 10 to around 30 . The correlation coefficients between the number of sheep and the number of juvenile (Pearson correlation, $r=-0.82, p=0.09$ ) and adult $(r=-0.85, p=0.07)$ voles were large and negative, but not statistically significant. The sheep were removed in early spring 2018 and the recovery of the vegetation was immediately visible, but the vegetation in the study area was never heavily destroyed and still contained both food and cover for the voles. The eagle owl first bred on the island in 2012 and attempted to breed every year until 2016, and then again in 2018 (Table 1; Fig. 2). In 2012-2016, it appeared that only a single chick survived to fledging, in 2012. Two chicks fledged in 2018 (Frode Johansen, pers. comm.).

The years were grouped into those with or without owl nesting attempts, sheep grazing, and radio tracking (Table 4). Because the first two factors only differed by one year, no significant differences between them could be expected, and the results were similar (Table 4). Water voles were significantly heavier and in larger numbers without both factors operating. The radio tracking factor worked contrary to the other two, with larger mass and numbers in years with tracking (Table 4). This was particularly significant for adult mass and juvenile numbers. The difference in the number of adults, [(adults+subadults)-adults], shows the same pattern (ANOVA, $F=4.2, p<0.05$ ). This implies that the mortality in subadults was greater in years of owl breeding attempts and/or sheep grazing than in years of radio tracking, when this mortality was close to zero (Table 4).

The mass of both juveniles and adults dropped consistently with increasing level of predation; radio tracking (no owl) vs. 1 owl present vs. owl breeding attempt and sheep grazing: juveniles 119.2/115.7/100.6 g (ANOVA, $F=5.4$, $p<0.05)$, adults $213.6 / 194.5 / 187 \mathrm{~g}(F=9.8, p<0.01)$. The
Table 3 Mass of juvenile and adult water voles from the pellet and selection samples

\begin{tabular}{|c|c|c|c|c|c|c|}
\hline \multirow[t]{2}{*}{ Sample } & \multicolumn{3}{|c|}{ Juveniles } & \multicolumn{3}{|l|}{ Adults } \\
\hline & Mean & SD & $n$ & Mean & SD & $n$ \\
\hline Pellet sample & 114.4 & 26.4 & 75 & 179.1 & 28.4 & 36 \\
\hline Selection sample & 114.6 & 26.6 & 75 & 178.4 & 39.8 & 36 \\
\hline Total sample & & & 1854 & & & 420 \\
\hline
\end{tabular}

Mean mass in g, 1 standard deviation (SD) and number of voles $(n)$. Test between pellet and selection samples: ANOVA, $F=0.00_{1},{ }_{220}, p>0.05$. The total sample is the number of voles marked on all islands 
Table 4 Mean mass $(g)$ of adult (excluding subadults) and juvenile water voles from Trolløya for three different factors; owl breeding attempts, sheep grazing, and radio tracking $(n=5,6$, and 3 years)

\begin{tabular}{|c|c|c|c|c|c|c|c|c|c|c|}
\hline & \multicolumn{2}{|l|}{ Mean } & \multicolumn{2}{|c|}{ ANOVA } & \multicolumn{2}{|c|}{ Maximum } & \multicolumn{2}{|c|}{ Numbers } & \multicolumn{2}{|c|}{ Difference } \\
\hline & No & Yes & $F$ & $p=$ & No & Yes & No & Yes & No & Yes \\
\hline \multicolumn{11}{|l|}{ Adults } \\
\hline Owl breeding & 201.7 & 185.7 & 7.3 & 0.02 & 250.4 & 224.2 & 28.6 & 25.7 & 4.5 & 18.7 \\
\hline Sheep grazing & 202.7 & 187.0 & 7.1 & 0.02 & 250.0 & 228.3 & 30.3 & 24.4 & 4.2 & 16.9 \\
\hline Radio tracking & 189.8 & 213.6 & 16.5 & 0.002 & 234.6 & 256.0 & 26.9 & 29.0 & 13.3 & 0.7 \\
\hline \multicolumn{11}{|l|}{ Juveniles } \\
\hline Owl breeding & 115.8 & 99.6 & 9.2 & 0.01 & 179.3 & 169.4 & 132.9 & 115.6 & & \\
\hline Sheep grazing & 117.5 & 100.6 & 11.4 & 0.007 & 174.6 & 176.5 & 144.2 & 107.2 & & \\
\hline Radio tracking & 105.7 & 119.3 & 3.5 & 0.09 & 176.0 & 178.3 & 109.0 & 175.7 & & \\
\hline
\end{tabular}

Included are also a test of mass between years with (yes) and without (no) the factor, maximum mass and the numbers of voles. Difference is the number of adults including subadults subtracted by the number of adults only. For juveniles, mass includes only those captured from July, while numbers also include those captured in June number of juveniles dropped similarly; 175.7/112.7/107.2 $(F=4.9, p<0.05)$

Conversely, the eagle owl produced most fledglings in the two years with largest numbers of adult voles in spring (2012 and 2018). Other variables were tested against owl breeding vs. no owl breeding and sheep present vs. sheep absent (Mann-Whitney tests, $z=0.1-1.6, p>0.05$ ): the number of voles in the pellet sample and the number of ear tags in the pellet sample (also tested against the previous year's numbers).

Juveniles were grouped into those larger and smaller than $120 \mathrm{~g}$ (from July, Trolløya), and the two groups tested against years with and without breeding owls and presence of sheep (expected values set to equal). The number of juveniles weighing more than $120 \mathrm{~g}$ was much larger without than with breeding owls and the presence of sheep, 2.3 and 2.6 times larger, respectively (Chi-square test, $\chi^{2}$ ${ }_{3}=34,9, p<0.001, n=5 / 7$ years and $\chi_{3}^{2}=29.8, p<0.001$, $n=6 / 6$ years). This increased number of large juveniles was the most significant difference between the "without" and "with" groups.

The negative effect of sheep was supported by trapping results from other islands with sheep presence (2003-2005; Lille Buøya, Nord-Solvær, Sør-Solvær, and Storrossøya, Table 2), all these vole populations collapsed almost completely and did not recover. However, other factors were also significant, such as flooding on Storrossøya (in 2005) and overgrazing by the voles themselves on Sør-Solvær (in 2004). Conversely, on Gammholmen, a very small island where sheep were absent, the surveys suggested healthy populations of water voles in most years.

\section{Influence of weather}

The weather variables temperature, wind speed, and precipitation had very little significance on the vole populations in either winter or summer and when including both the total sample and Trolløya alone. Mean and maximum summer (June-August, 92 days) temperatures were tested against multiple variables: number of juveniles and adults, the mass of juveniles (in July and August) and adults, the production of young per adult female, the number of voles and ear tags in the pellet samples and the proportion of voles in the diet of the eagle owl (Pearson correlation, $p>0.05, n=15-20$ years and islands). Spring temperatures (April-May, 61 days) and winter temperatures (November-March, 152 days) likewise gave no significant correlations.

Only one statistically significant effect of weather was found: the mean summer wind speed was positively correlated with the number of adults (Pearson correlation, $r=0.69, p=0.001, n=18)$. This relationship was also significant for Trolløya alone $(r=0.58, p<0.05, n=13)$, mostly due to the number of adult females. The correlation between the number of adults and minimum winter temperature was also quite large, (Pearson correlation, $r=0.49, p=0.07, n=14)$.

In 2010, low temperatures and little or no snow cover during the winter led to unusually deep frost penetration in the ground. This had a profound influence on the water vole population on Trolløya, which dropped to an all-time low regarding the number of young the following summer (Table 1; Fig. 2). Because the recapture rate 2.3 was the highest ever recorded (number of recaptures/ number of individual voles, mean across all years was $1.6 \pm 0.3, n=13$ years), the low population size was not a result of relaxed trapping due to fewer voles present. In the winter 2009-2010, the mean minimum temperature was $-13.1{ }^{\circ} \mathrm{C}$ and mean temperature $-0.7{ }^{\circ} \mathrm{C}$, both the lowest of any winter. 


\section{Daily activity}

The numbers of voles trapped were higher during the middle of the day and dropped off in late evening (Table 5). The curve of captures between 0700 and $2300 \mathrm{~h}$ was concave rather than convex. This pattern was not much different between adults and juveniles or between the sexes. Both juvenile and adult voles were trapped more often between 1200 and 1959 h (61 and 63\% of captures, Table 5). Activity recordings from the radio transmitters gave similar, but less clear, results. This method recorded activity both above and below ground, not just above ground as by trapping.

\section{Discussion}

The eagle owl consumed largely water voles, supplemented with a small proportion of birds, and a large proportion of the water vole population was consumed each year. The density of the eagle owl population in the archipelago is unique, and this study supports a strong link between the populations of these two species. In the main study site on Trolløya, vole density was generally high and the production of young varied fourfold between years. This variation may be smaller than normally associated with a regular population cycle and no regularity in peak years was seen. A set of multiple factors affected the population by reducing its numbers through reduced survival and production of young, which may be explained by these scenarios:

(a) A constant predation by eagle owls seemed to keep the water vole population mostly within limits that seemed "sustainable". The extra predation predicted due to owl breeding attempts was detectable, but small because nearly all breeding attempts were unsuccessful. The effect of predation was clearest in three sum-

Table 5 The percentage of juvenile and adult water voles captured in 4-h intervals between 0800 and $2359 \mathrm{~h}$ (including all recaptures), and the $\%$ of activity recorded from juvenile, adult, and subadult (in April) radio-collared water voles on Trolløya in 4-h intervals during all $24 \mathrm{~h}$

\begin{tabular}{|c|c|c|c|c|c|}
\hline \multirow[t]{2}{*}{ Hours } & \multicolumn{2}{|c|}{ Captured (\%) } & \multicolumn{3}{|c|}{ Radio-tracked (\% Active) } \\
\hline & Juveniles & Adults & Juveniles & Adults & Subadults \\
\hline $2400-0359$ & & & 14.2 & 36.5 & \\
\hline $0400-0759$ & & & 26.4 & 35.0 & 14.8 \\
\hline $0800-1159$ & 21.3 & 23.1 & 34.1 & 37.9 & 22.1 \\
\hline $1200-1559$ & 30.0 & 31.4 & 32.9 & 34.5 & 24.6 \\
\hline $1600-1959$ & 31.2 & 31.6 & 40.1 & 37.1 & 26.0 \\
\hline $2000-2359$ & 14.5 & 11.5 & 40.4 & 42.8 & 5.9 \\
\hline N/Overall mean & 4503 & 1726 & 31.4 & 37.3 & 18.7 \\
\hline
\end{tabular}

mers of intensive radio tracking, which temporarily protected the population in the study area. While this work was ongoing, the owls hunted elsewhere, which gave quite a dramatic effect on the water vole population. In particular, this resulted in increases in the number of young and the mass of adults. The presence of humans may benefit populations of small mammals by deterring predators (Suraci 2019), as does predator exclusion (Hanski et al. 1991; Korpimäki and Norrdahl 1998; Carlsen et al. 2000; Norrdahl et al. 2004; Sundell 2006; Trebatická et al. 2008). In one of these years on Trolløya, the number of young became so large that the vegetation was clearly affected. A density of 200 young per hectare may have been close to the carrying capacity of the vegetation (sensu Wolff et al. 2002; Briner et al. 2007).

(b) Predation affected the numbers surviving from one autumn to the next spring, but as long as enough survived, the population could quickly recover (sensu Stoddart 1971; Erlinge et al. 1983; Boonstra and Krebs 2006). Predation also reduced the number of young during the summer, in particular by removing the early litters. Young born later might face the winter at a lower mass, which could reduce survival, but this hypothesis was not supported. Predation also reduced the mass of the adults, possibly through stress (Norrdahl et al. 2004; Boonstra and Krebs 2012). Annual predation rates could account for nearly all mortality, as found by Erlinge et al. (1983).

(c) Adult and male voles were overrepresented in the diet of the eagle owl, but the hypothesis that those eaten were of lower mass and hence most likely in poorer condition as found by Melis et al. (2011), was not supported (sensu Sunde et al. 2012). The lower proportion of males among adults than among juveniles may have resulted from higher mortality rates among males.

(d) Predation effectively removed adults during the summer, so that very few females lived long enough to produce more than 1-2 litters (sensu Stoddart 1971). Because a large proportion of the early cohorts was also removed, very few, if any, young could reproduce in their summer of birth (sensu Nazarova 2013). This would very effectively check population growth and hinder population outbreaks (Erlinge et al. 1983). More intense predation in the summer of 2012 may have effectively reduced the numbers of both adult and young voles, giving fewer young than could have been expected.

(e) Such intensive predation could have a negative feedback on the eagle owl by reducing its potential prey base. This in turn probably reduced the owl breeding success. In years with a very low water vole population, the eagle owl would have to hunt elsewhere and/ 
or switch to other prey (birds, such as gulls and waders). This would have reduced the predation pressure on the remaining vole population, allowing it to increase faster. If so, a dynamic feedback loop may exist between the water vole population and the breeding of eagle owls. The eagle owl acted as a stabilizing factor on the water vole population, but did not enforce population crashes. The high survival of water voles from 2010-2011 may have resulted from a switch of prey by the eagle owl or even by the death of owls. The even better survival from 2017-2018 is more difficult to explain, and may have been the result of the owls hunting elsewhere, supported by the fact that very few owl pellets were found in May 2018.

(f) Grazing by domestic sheep may severely reduce a population of water voles and perhaps cause local extinction (Frafjord 2014). In this study, sheep grazing may have exacerbated the effect of predation, but since the presence of sheep and the eagle owl breeding attempts occurred concurrently, their effects were difficult to separate. On Trolløya, the initial number of sheep was small and the vegetation in the study area was not destroyed, it still gave cover for the voles. Grazing may not have been intensive enough to cause a dramatic decline in the vole population, on other islands it did and appeared to have a long-lasting effect.

(g) Weather extremes could cause disasters to the water vole population. In one especially cold winter with little snow, frost penetrated unusually deep into the ground, one meter or more (sensu Johnsen et al. 2017). A frozen ground with no protective snow cover would reduce food availability and increase metabolism. This reduced the vole population most dramatically, not only on Trolløya, but probably across all islands in the archipelago. An eagle owl breeding failure followed (sensu Bevanger et al. 2011), which may have reduced the vole predation rate and allowed a subsequent rapid increase in the vole population. Another extreme weather event was heavy rain causing flooding of low-lying fields with poor drainage. On at least one island, this caused a dramatic population crash in the spring, but had little effect on other islands with better drainage. Extreme weather events may have dramatic effects, but are comparatively rare.

(h) Summer weather appeared to have little or no effect on the breeding in water voles: The animals were probably well protected in the vegetation and underground. However, adults appeared to survive better when there was more wind, perhaps because wind (noise) made hunting more difficult for the eagle owl?

(i) The hypothesis that the voles were much more active during daylight hours was supported. The water vole reduced its activity, especially above ground, at night, most likely an adaptation to avoid the night-hunting eagle owl. It appears likely that the eagle owl hunted most successfully at dawn and dusk, when both vole and owl activity coincided most (sensu Penteriani and Delgado 2019).

In a more natural situation with no sheep and no extreme weather events, predation by the eagle owl would in most years be the single most important mortality factor. Variations in the energetic needs of the eagle owl due to breeding and the number of chicks could result in varying predation pressure on the water vole both across time and space. For a water vole population, the most vital statistics are the numbers that survive to breed next year and perhaps the number of litters per female (sensu Johnsen et al. 2017). As long as enough voles survive, predation on the "surplus" voles should have little effect on the population. In this study, the more commonly used captures/100 trap nights $(24 \mathrm{~h})$ was less suited but was roughly estimated and extrapolated based on the overall mean numbers trapped/year to somewhere between 28 and 37 adults and 79-105 juveniles.

From data on BMR and mass for five owl species given by Wijnandts (1983), I estimated the regression line: BMR $(\mathrm{kJ})=29.29+0.29 *$ mass in $\mathrm{g}$ (excluding the snowy owl Nyctea scandiaca that deviated much) for owls in general. For an owl weighing $2.4 \mathrm{~kg}$ (approx. mean for a northern eagle owl, Penteriani and Delgado 2019) I estimated BMR to be $725 \mathrm{~kJ} /$ day. Using an energy density of $7.7 \mathrm{~kJ} / \mathrm{g}$ fresh mass of a common vole Microtus arvalis (Wijnandts 1983) as an approximation, a vole of $100 \mathrm{~g}$ would give $770 \mathrm{~kJ}$ $(200 \mathrm{~g}=1540 \mathrm{~kJ})$. Although this is only a very rough estimate, it indicates that an adult eagle owl may require about one juvenile water vole $(100 \mathrm{~g})$ day $^{-1}$. The energetic need of an incubating female increases and rapidly growing owlets would need ever-increasing amounts of food (Wijnandts 1983; Penteriani and Delgado 2019). If an average vole eaten by the owls weighed $150 \mathrm{~g}$, one owl would need 270 voles $\mathrm{y}^{-1}$. This is about twice the number found in pellets, indicating that less than half of the produced pellets were found (many disintegrate during the summer).

In the study area on Trolløya, an average of 174 juvenile and adult voles disappeared each year, probably nearly all through predation (sensu Stoddart 1971). The population of water voles across all of Trolløya might support about (or nearly) two adult eagle owls. To account for the extra demands of breeding, the owls would have to hunt in a wider area, which they did. Bevanger et al. (2011) estimated the home range of one radio-tagged adult male eagle owl in this archipelago to be $3.2 \mathrm{~km}^{2}$. This is more than ten times the size of Trolløya.

In spring, the mass of female water voles increased later than that of males. In summer, their increased mass relative to males resulted from their extra mass during pregnancies. 
A litter of 4.5 young at $5 \mathrm{~g} /$ young is $22.5 \mathrm{~g}$ (Stoddart 1971; Nazarova 2013), easily accounting for the weight difference between females and males in summer. Many males also lost mass during the summer, due to the costs of searching and fighting for females (Frafjord 2016). Females should theoretically be able to produce 3-4 litters during May-July (sensu Stoddart 1971; Nazarova 2013), but the demands of reproduction may have increased the risk of being predated. This fact alone could explain the modest population increase of maximum 3.5 times during the summer on Trolløya.

Acknowledgements Frode Johansen was an invaluable helper during all the years of field operations, ensuring safe transportation by boat at all times. Rob Barrett, as always, patiently corrected the manuscript's style and spelling. I would like to express my gratitude to Troms $\varnothing$ Museum in accepting such a long-term study. The comments of Vidar Selås and two anonymous reviewers greatly improved the manuscript. This research did not receive any specific grant from funding agencies in the public, commercial, or not-for-profit sectors.

Funding Open Access funding provided by UiT The Arctic University of Norway.

\section{Declarations}

Conflict of interest Permission to trap and mark water voles was given by the Norwegian Environment Agency.

Ethical approval No further permissions or approval were needed. In Norway, simple identity marking does not require an ethical evaluation. Care was taken to handle the animals gently and release them as quickly as possible, in compliance with national ethical guidelines. Trapping and handling caused no mortality.

Open Access This article is licensed under a Creative Commons Attribution 4.0 International License, which permits use, sharing, adaptation, distribution and reproduction in any medium or format, as long as you give appropriate credit to the original author(s) and the source, provide a link to the Creative Commons licence, and indicate if changes were made. The images or other third party material in this article are included in the article's Creative Commons licence, unless indicated otherwise in a credit line to the material. If material is not included in the article's Creative Commons licence and your intended use is not permitted by statutory regulation or exceeds the permitted use, you will need to obtain permission directly from the copyright holder. To view a copy of this licence, visit http://creativecommons.org/licenses/by/4.0/.

\section{References}

Bevanger K, Bartzke G, Brøseth H, Dahl EL, Gjershaug JO, Hanssen F, Jacobsen K-O, Kvaløy P, May R, Meås R, Nygård T, Refsnæs S, Stokke S, Thomassen J (2011) Optimal design and routing of power lines; ecological, technical and economic perspectives (OPTIPOL). Progress Report 2011. NINA Report No. 762

Boonstra R, Krebs CJ (2006) Population limitation of the northern red-backed vole in the Boreal forest of northern Canada. J Anim Ecol 75:1269-1284
Boonstra R, Krebs CJ (2012) Population dynamics of red-backed voles (Myodes) in North America. Oecologia 168:601-620

Boonstra R, Andreassen HP, Boutin S, Husek J, Ims RA, Krebs CJ, Skarpe C, Wabakken P (2016) Why do the Boreal forest ecosystems of northwestern Europe differ from those of western North America? Bioscience 66:722-734

Briner T, Favre N, Nentwig W, Airoldi J-P (2007) Population dynamics of Microtus arvalis in a weed strip. Mamm Biol 72:106-115

Carlsen M, Lodal J, Leirs H, Jensen TS (2000) Effects of predation on temporary autumn populations of subadult Clethrionomys glareolus in forest clearings. Z Säugetierk 65:100-109

Cerqueira D, De Sousa B, Gabrion C, Giraudoux P, Quéré JP, Delattre $P(2006)$ Cyclic changes in the population structure and reproductive pattern of the water vole, Arvicola terrestris Linnaeus, 1758. Mamm Biol 71:193-202

Erlinge S, Göransson G, Hansson L, Högstedt G, Liberg O, Nilsson IN, Nilsson T, von Schantz T, Sylvén M (1983) Predation as a regulating factor on small rodent populations in southern Sweden. Oikos 40:36-52

Frafjord K (2003) Do eagle owls select larger water voles? Fauna Norv 23:42-47

Frafjord, K (2006) A live trap for water voles Arvicola terrestris. Fauna 59:116-120 (in Norw, with Engl summary)

Frafjord K (2014) Grazing by sheep Ovis aries reduces island populations of water voles Arvicola amphibius. Fauna Norv 34:79-81

Frafjord K (2016) Influence of reproductive status: home range size in water voles (Arvicola amphibius). PLoS ONE 11:e0154338

Getz LL, Oli MK, Hofmann JE, McGuire B (2006) Vole population fluctuations: factors that initiate and determine intervals between them in Microtus ochrogaster. J Mamm 87:387-393

Hansen TF, Stenseth NC, Henttonen H, Tast J (1999) Interspecific and intraspecific competition as causes of direct and delayed density dependence in a fluctuating vole population. Proc Natl Acad Sciences USA 96:986-991

Hanski I, Henttonen H (2002) Population cycles of small mammals in Fennoscandia. In: Berryman A (ed) Population cycles. The case for trophic interactions. Oxford University Press, Oxford, pp 44-68

Hanski I, Hansson L, Henttonen H (1991) Specialist predators, generalist predators, and the microtine rodent cycle. J Anim Ecol 60:353-367

Henttonen H (1977) Interspecific competition between small rodents in Subarctic and Boreal ecosystems. Oikos 29:581-590

Hörnfeldt B (2004) Long-term decline in numbers of cyclic voles in Boreal Sweden: analysis and presentation of hypotheses. Oikos 107:376-392

Johnsen K, Boonstra R, Boutin S, Devineau O, Krebs CJ, Andreassen HP (2017) Surviving winter: food, not habitat structure, prevents crashes in cyclic vole populations. Ecol Evol 7:115-124

Korpimäki E, Norrdahl K (1991) Do breeding nomadic avian predators dampen population fluctuations of small mammals? Oikos 62:195-208

Korpimäki E, Norrdahl K (1998) Experimental reduction of predators reverses the crash phase of small-rodent cycles. Ecology 79:2448-2455

Krebs CJ (2013) Population fluctuations in rodents. The University of Chicago Press, Chicago

Melis C, Holmern T, Ringsby TH, Sæther B-E (2011) Who ends up in the eagle owl pellets? A new method to assess whether water voles experience different predation risk. Mamm Biol 76:683-686. https://doi.org/10.1016/j.mambio

Moorhouse TP, Gelling M, Macdonald DW (2008) Effects of forage availability on growth and maturation rates in water voles. $\mathrm{J}$ Anim Ecol 77:1288-1295

Nazarova GG (2013) Effects of seasonal, ontogenetic, and genetic factors on lifespan of male and female progeny of Arvicola 
amphibius. Front Genet. https://doi.org/10.3389/fgene.2013. 00100

Norrdahl K, Heinilä H, Klemola T, Korpimäki E (2004) Predatorinduced changes in population structure and individual quality of Microtus voles: a large-scale field experiment. Oikos 105:312-314

Oli MK (2019) Population cycles in voles and lemmings: state of the science and future directions. Mamm Rev 49:226-239. https://doi. org/10.1111/mam.12156

Penteriani V, Delgado MM (2019) The eagle owl. T AD Poyser, London

Saucy F (1994) Density dependence in time series of the fossorial water vole, Arvicola terrestris. Oikos 7:381-392

Stoddart M (1971) Breeding and survival in a population of water voles. J Anim Ecol 40:487-494

Strachan R (1998) Water vole conservation handbook. George Street Press Limited, Staffordshire

Sunde P, Forsom HM, Al-Sabi MNS, Overskaug K (2012) Selective predation of tawny owls (Strix aluco) on yellow-necked mice (Apodemus flavicollis) and bank voles (Myodes glareolus). Ann Zool Fennici 49:321-330
Sundell J (2006) Experimental tests of the role of predation in the population dynamics of voles and lemmings. Mamm Rev 36:107-141

Suraci J (2019) Fear of humans as apex predators has landscape-scale impacts from mountain lions to mice. Ecol Lett 22:1758-1586

Trebatická L, Sundell J, Tkadlec E, Ylönen H (2008) Behaviour and resource use of two competing vole species under shared predation risk. Oecologia 157:707-715

Wijnandts, H (1983) Ecological energetics of the long-eared owl (Asio otus). $\mathrm{Ph} \mathrm{D}$ thesis, Rijksuniversiteit te Groningen

Wolff JO, Edge WD, Wang G (2002) Effects of adult sex ratios on recruitment of juvenile gray-tailed voles, Microtus canicaudus. J Mamm 83:947-956

Publisher's Note Springer Nature remains neutral with regard to jurisdictional claims in published maps and institutional affiliations. 